\title{
Perceiving Exploding Tropes
}

\author{
Jan Almäng
}

Penultimate version. Final version is published in Grazer Philosophische Studien Grazer Philosophische Studien, Volume 93, Issue 1, pages $42-62$

http://booksandjournals.brillonline.com/content/journals/10.1163/18756735-09301003

\begin{abstract}
The topic of this paper is the perception of properties. It is argued that the perception of properties allows for a distinction between the sense of the identity and the sense of the qualitative nature of a property. So, for example, we might perceive a property as being identical over time even though it is presented as more and more determinate. Thus, you might see an object first as red and then as crimson red. In this case, the property is perceived as identical over time, even though the sense of the qualitative nature (the redness, the crimson redness) of the property is changing. The distinction between the sense of identity and the sense of quality is explicated in terms of perceiving a particular property, a trope, and perceiving it as an instance of a universal. It is subsequently argued that the perceived tropes cannot constitute the phenomenal character of the perceptual experience.
\end{abstract}

\section{Introduction}

The topic of the present paper is the perception of tropes. It offers a novel argument to the effect that, even though we can perceive tropes, the perceived tropes themselves are not the constituents of the phenomenal character of our perceptions. Despite the fact that tropes feature prominently in the modern ontological discussion of properties, and despite the fact that properties feature prominently in most theories of perception, tropes rarely feature in discussions concerning the nature of perception. ${ }^{1}$ There are obviously exceptions; the claim that we can perceive tropes is present already in Husserl's Logical Investigations, where it is defended for perhaps the first time in the literature (Husserl 1900/01, Mulligan 1995, 173ff.). But the literature on the possibility of perceiving tropes is not vast, and I believe that my argument is new.

A trope is a particular property. If two objects exactly resemble each other with respect to some property, they will have different tropes. Properties are according to trope-theory particulars just as much as the substance ${ }^{2}$ that exemplify them. It is important to note that this conception of tropes does not entail nominalism. The conception of tropes I will rely on in this paper is neutral as to whether tropes are particular instances of universals (as realists claim) or not (as nominalists claim). ${ }^{3}$

\footnotetext{
${ }^{1}$ There are obviously exceptions to this. Thus, Campbell (1981), Lowe (1998, 2008), Mulligan, Simons and Smith (1984) and Mulligan (1999) all argue that we perceive tropes and Burge (2010) at least seems sympathetic to the claim, whereas Levinson (2006) argues that we do not. Kriegel (2004) uses trope theory to illuminate the metaphysics of phenomenal states and Nanay (2012) uses it to illuminate intentional content, but they do not explicitly argue that we perceive tropes. I have however not come across any literature that discusses trope theory in relation to perceptual constancies and perceptions of change, which is what I will do in the present paper.

${ }^{2}$ The term "substance" is used to refer to ordinary objects, such as cats, trees and stones.

${ }^{3}$ The literature on tropes is vast. For nominalistic versions of trope theory, see for example Campbell (1981), Mulligan, Simons and Smith (1984), Williams (1953). For realistic versions of trope theory that combine a
} 
A recurring problem for most theories of perception is to determine the proper object of an act of perception. ${ }^{4}$ Is it a state of affairs, a substance or a trope? According to some the objects of normal acts of perception are substances, such as cars, cats, trees and human beings, but not states of affairs (Smith 1979). Others are happy to include both states of affairs and substances as the objects of perceptual acts (Searle 1983). Another option is to hold that it is tropes that are the immediate objects of perceptual acts, and that it is only through perceiving tropes that we are indirectly seeing substances (Campbell 1981, 481). A third option would be to claim that it is universals that are the immediate objects of perceptual acts (Johnston 2004).

My own position is inclusive. I will assume that we can perceive both properties and substances. There is no order of priority here. They are both the primary objects of a visual experience. I will argue that we are perceptually presented ${ }^{5}$ with properties as tropes. This claim is consistent with the notion that we can also be perceptually presented with universals.

The next section will present a couple of variations of an example of a perceptual illusion once introduced by David Woodruff Smith. Section three argues that these examples show that perception has a certain structure. Section four argues that these examples show that we can perceive tropes. The fifth section presents an argument against object-involving theories of phenomenal character. It is argued that the perceived tropes of a perceptual experience cannot be part of the phenomenal character of that experience. And the sixth section concludes the paper with some brief remarks on phenomenal tropes.

\section{Exploding Perceptions - Variations on a Smithian Theme}

David Woodruff Smith has in a series of papers (Smith 1979, 1984, 1986) and a book (Smith 1989) argued that the descriptive content of an act of perception does not determine the reference of the said perception. Smith's arguments are based on various thought experiments where we initially have a perceptual illusion and subsequently realize that we have been the subjects of such an illusion.

In "The Case of the Exploding Perception", Smith presents a variety of examples of perceptual illusions. Let us take a look at the first of these cases:

(a) A man called "Smith" approaches a bobby at the London Wax Museum. As he starts talking to him, he realises that he is not talking to a bobby at all. He is not even talking to a human being but to a figure of wax. (Smith 1979, 239)

When Smith the tourist realises that he is not talking to a bobby but to a figure of wax, his perception explodes. Smith is well aware that a human being cannot be identical to a wax figure and that neither can it turn into one. The object before the explosion is classified as a human being, whereas it is classified as a wax figure after the explosion.

Smith is nevertheless in some sense presented with the same object before and after the explosion. It is true that the object is classified as belonging to different kinds before and after the explosion. But it is the same object that is classified in different ways. According to Smith the philosopher, the proper conclusion to draw from this example is that there are two types of

commitment to tropes with a commitment to universals, see for example Husserl (1901), Lowe (2006), Mertz (1996) and Svennerlind (2008).

${ }^{4}$ The term "object" is used in as wide a sense as possible. Anything that a perception can be about, be it an event, a process, a substance, a property or a state of affairs, can thus be a perceptual object.

${ }^{5}$ A note on formulations such as "x perceives $y$ " and " $x$ is perceptually presented with $y$ ": Unless otherwise specified, I will use these formulations in the non-factive sense of $x$ representing $y$, regardless of whether the perception is veridical. The formulation " $\mathrm{x}$ is perceptually related to $\mathrm{y}$ " will on the other hand be used in order to indicate that $\mathrm{x}$ is veridically perceiving $\mathrm{y}$. 
directedness involved in this case, one of acquaintance and one of interpretation. The perceiver is throughout this process acquainted with the same object. But the object is interpreted differently before and after the explosion. It is important to note that the acquainting sense is independent of the classificatory sense. Smith is in this case perceptually related to a figure of wax throughout the process, but this figure is presented as a normal human being before the explosion and as a figure of wax after the explosion. (Smith 1979, 243)

On Smith's account the acquainting sense determines the reference to the object whereas the classificatory sense interprets the object as being of a certain kind. Smith compares his account to Husserl's account of perception. Husserl distinguishes between two basic components in the act of perception: an $\mathrm{X}$ determining the particular object of perception and a descriptive content consisting of a complex of predicate senses referring to the properties of the object. Smith and Husserl agree that the descriptive content does not determine the object of perception. (Smith 1979, 258)

Smith and Husserl agree that it is the X-content, or the acquainting sense, that determines the object of the perception. This content is de re. It functions independently from the predicate senses attributing various properties to the object. We can perceive an object even if we are mistaken with respect to which properties the object has. Hence, it is because the Xcontent is invariant that a sequence of perceptual acts with different descriptive contents nevertheless can present us with the same object. (Smith 1979, 258)

So far we have studied Smith's account of how it is possible for us to be presented with substances such as human beings or figures of wax. I now want to make a suggestion that at first might sound astonishing. It is not only with respect to the perception of substances that we can distinguish between the X-content and the descriptive content. The perceptual content presenting us with the properties of a substance also has this structure. There is one sense that determines the particularity of the property, and one that determines the qualitative character. The qualitative character of a property can be conceived of as the universal the property is an instance of, or the resemblance class it belongs to, depending upon whether one is a realist or a nominalist with respect to properties.

Perceptual explosions can occur not only when we perceive substances, but also when we perceive properties. Consider first the following case:

(b) Brian perceives a piece of ice melting. Gradually the colour of the ice turns from white to dark grey.

In this case it is quite clear that Brian perceives an object that is gradually changing its properties with respect to colour. So, unlike the case described in (a), this is not a case of a perceptual explosion of any kind. The perception is veridical throughout the sequence and presents an object that is changing its colour.

Let us contrast these cases with two other cases, where there is a perceptual explosion involved.

(c) Catherine is perceptually presented with a white cube. As she approaches the cube, she perceives that it is not white but dark grey.

This is a normal case of discovering that one has been exposed to a perceptual illusion. It differs from (a) in the sense that it is not the kindhood of the substance that explodes. It differs from (b) in the sense that the property of the substance explodes. Unlike Brian, Catherine does not perceive the substance change its properties. Rather, she experiences a change in the way she is perceptually presented with the property. She realises that she has been mistaken about 
the colour of the object, but she does not see the object change its colour. So we can call this a case of a property explosion (Smith 1979, 247 discusses a similar case).

Consider now a fourth case where the perception of a property is changing:

(d) Diana perceives a ball but cannot clearly see the colour of it. As she goes nearer, the perception becomes more determinate. First she perceives that it is dark. Then she perceives that it is blue. Finally she perceives that it is navy blue.

This case is different from (c) in that there is no illusion involved. Diana is not perceptually presented with any property of the object that it lacks.

The case described in (d) could probably best be illustrated by use of the notions of determinable and determinate (cf. Johnson 1921, 173ff). A determinable is a general property. Thus, colour and shape are determinables. When an object exemplifies a property, it always exemplifies a determinate property. Being cubical and being spherical are for example two determinate properties of the determinable shape. Determinates are obviously related to determinables. Whenever an object exemplifies a determinate, it also exemplifies its determinable (cf. Johansson 2000).

It is at this point worth noting that perceptual and linguistic representations often represent a property that is neither of the highest determinable (such as colour) or the lowest determinate (such as a specific shade of red), but rather a property that is neither at the highest nor at the lowest end of the scale (such as being red). These properties function as determinables in relation to some properties and as determinates in relation to other properties.

Armed with these resources we can now describe (d) as a case in which Diana gradually perceives the colour as more and more determinate. The perceptual content follows the scale from highest determinable (colour) to lowest determinate (navy blue) in the sense that it represents properties that are successively more determinate.

What characterizes cases (c) and (d) is that in one sense of the word, the substance is presented as having different properties throughout the specious present, but in another sense it is not. Catherine first perceives the substance as being white and then dark grey. And Diana goes from perceiving the substance as merely coloured to perceiving it as navy blue. So our cases are clearly different from ordinary cases of perceiving an object as having the same property over time. ${ }^{6}$

But our two cases are also different from perceptions of change. The object is not perceived as changing with respect to the property involved. Even though the property appears as successively more determinate, there is a sense in which Diana is perceptually presented with the same property. So in another sense of the word, the perceivers have no sense of perceiving different properties through time. We can express this by saying that the object of perception is characterized by a certain perceptual constancy. Let us consequently refer to case (b) as a case of property change and cases (c) and (d) as cases of property constancy.

In order to characterize these cases, I would like to make a tentative distinction between the sense of identity and the sense of quality in the perception of properties. Both the sense of identity and the sense of quality of the colour of the object is changing in Brian's case. Hence, the object is perceived as changing. In the property constancy cases however, what is changing is the sense of the quality of the property. But even though the sense of quality is changing, the property itself is not perceived as changing since the sense of identity of the property is invariant throughout the sequence.

\footnotetext{
${ }^{6}$ They are also different from the phenomenon of colour constancy. In the latter case the phenomenal character may vary, but you are nevertheless presented with the same colour. One might for example perceive an instance of a specific shade of red as being the same instance of that specific shade of red even though the illumination in the room varies during the perception (cf. Chalmers 2006, 84ff, Mulligan 1999, 175).
} 


\section{The Intentional Structure of Perceiving Properties}

What lessons, if any, can be learned from the above cases? In the present section I shall argue that there is a clear phenomenological difference between case (b) on the one hand and cases (c) and (d) on the other hand. The difference is not merely that Brian judges that the object is changing whereas Catherine and Diana judges that the object is not changing. The difference is a perceptual difference.

The argument that I am about to develop might be seen as a version of Siegel's (2010) method of phenomenal contrast for discovering the content of a perceptual experience. The general idea behind Siegel's method is to contrast two perceptions with different phenomenal characters and examine whether the phenomenal difference is best explained by there being a difference in content between the two cases. As Siegel attempts to outline a general theory for how to discover which properties can be presented in perceptual content her approach might seem suitable here.

There is however an important difference between Siegel's method and my approach. My argument employs Siegel's method up to a certain point. I will argue that contrasting cases can help us see the structure of the perceptual presentation of properties. I will subsequently argue that the best explanation for the fact that perception has this structure is that we perceive properties as tropes.

The alternative to conceive of the difference between property constancy and property change in terms of perceptual content would be to conceive of it as a difference in judgment. If there were no phenomenological difference between property constancy and property change, my distinction between the sense of identity and the sense of quality of the property would be superfluous. Sometimes we judge that the substance has changed, and sometimes that it has not changed. In cases (c) and (d) above, we judge that the substance has not changed. This, incidentally, seems to be Smith's account of the phenomenon (Smith 1979, 244f.).

The problem with this position is that cases of property constancy and property change are cognitively impenetrable. We perceive properties as constant or changing regardless of which judgments we make or which beliefs we have.

Consider for example a case of phenomenal vagueness. When looking at an object that is very slowly changing its shape, you will not see the object as changing. The perceptions exhibit property constancy. Yet if you look long enough at the object, you will after a certain period of time judge that the object has changed. So in this case you know that the object is continuously changing, but you do not perceive it. The situation is equivalent to the situation where you are looking at a clock. The hour hand is moving, and you know that it is moving. But you do not perceive it as moving. So a judgment to the effect that an object is changing in some respect is not a sufficient condition to actually see the object change. Nor is a judgment to the effect that an object is constant in some respect necessary in order to see the object as constant.

The same kind of argument can be construed with respect to perceptions of change and judgments of constancy. It is widely reported in the literature of perceptual illusions that an unchanging two-dimensional image in some cases can look like a three-dimensional object with an unstable and continuously changing shape. This is for example the case if a twodimensional image consists of a series of parallel lines. If the lines are arranged in a special way, so that some are grouped more closely than others, and if the perceiver attends to them 
for a period of time, it might appear to the perceiver as if the two-dimensional surface of the paper is three-dimensional with moving waves. (Wade 1977)

A related kind of perceptual illusion concerns movement. It is frequently reported in the literature that we can perceive movement in a stationary image - this is the phenomenon known as anomalous motion. The most famous is presumably the Fraser-Wilcox illusion, which has been developed in various ways by Akiyoshi Kitaoka (2006) In the illusion, movement is represented as more intense in the periphery of the visual field than in the centre of the visual field.

In both our illusions we perceive some property changing, even though we know that there is nothing that actually changes. In the first case we perceive the shape of the surface changing. In the second case we perceive the surface moving. But the movement of the surface changes as our attention shifts. In both cases it will look to us as if the object is changing with respect to some property - shape or movement. But we will nevertheless know that it is not changing. So in this case we may assume that observers judge that the property is constant. Yet they will nevertheless perceive the object as changing. This indicates clearly that judgments of property-constancy are not sufficient in order for us to perceive an object as constant with respect to some property. But it also indicates that a judgment to the effect that the object is changing is not necessary in order to perceive it as changing.

If my argument so far is correct, judging that a property is constant is neither a necessary nor a sufficient condition in order to perceive it as constant. And a judgment to the effect that an object is changing with respect to some property is neither a necessary nor a sufficient condition in order to perceive it as changing with respect to that property. But this shows that the difference between property constancy and property change cannot be found at the level of judgment. It must rather be found at the level of perceptual content itself.

Granted that there is a real perceptual difference between property change and property constancy, the question arises what this difference consists in. Smith argues that the lesson from perceptual explosions is that we must differentiate between the descriptive predicate senses and the non-descriptive acquainting sense when perceiving a substance. The cases of Brian and Catherine suggest that our perceptions of properties must have an analogous structure.

If the difference between the two cases is that Catherine (but not Brian) perceives the colour of the object as constant, even though she (as Brian) is presented with a sequence of changing shades of colour, there must be something that accounts across time for the identity of the property. So, what differentiates the two cases is that Catherine's perceptual content includes something that accounts for the identity of the property across time whereas Brian's perceptual content includes something that accounts for his sense of being presented with different properties across the perceptual sequence.

I have previously made a tentative distinction between the sense of identity and the sense of quality of perceiving a property. We are now in a position to conceive of how they are connected. The sense of identity of a property is, I have said, what accounts for Catherine's ability to see the object as having the same colour over time. The sense of quality, however, is what explains the fact that Catherine perceives the object as exemplifying different universals at different points in time. What characterises normal perceptual experiences is that the sense of identity changes when the sense of quality changes and vice versa. What characterises Catherine's case however is that the sense of identity and the sense of quality in some sense come apart.

We can express this by saying that in the case of constancy, the sense of quality can vary throughout the perceptual sequence, though the sense of identity remains invariant or constant. In perceptions of change, however, the sense of identity is not invariant throughout the sequence, and neither is the sense of quality. It is at this point important to emphasize that 
I am not claiming that a property has one part accounting for its identity and another part accounting for its quality. I am merely arguing that when we are perceptually presented with a property, perceptual content must be analysed as accounting for both the identity of the property and its quality.

Senses of identity and senses of quality may provisionally be conceived of as the parts of a Fregean perceptual content that represents properties of objects. Using the analogue with Smith's Husserlian account, we can say that the sense of identity corresponds to the acquainting sense, whereas the sense of quality corresponds to the predicative senses. The sense of identity accounts for our perception of a property as identical over time, whereas the sense of quality accounts for our perception of an object as being in a certain way - for example as being blue or spherical. In section five I will present an explicit argument to the effect that these senses cannot consist of Russellian contents.

If my account of the structure of the perception of properties is correct, the general structure of a perceptual content, presenting an object exemplifying a monadic property at a given moment in time, would be the following:

(i) $\mathrm{X}$ is $\mathrm{Y}$ with the quality $\mathrm{Q}$

In this case X presents an object, Y presents the identity of a property and Q presents the quality of the property.

In order to see how this works, let us analyse the perceptual experiences of Brian and Catherine across their temporal sequences. Let us assume that each of their sequences has four discernible temporal parts and that they are presented with the same quality at each temporal part. Brian's perceptual content with respect to the presentation of the colour of the object would then have the following structure across the perceptual sequence:

(b') The piece of ice is (at $\mathrm{t}_{1} a$ with the quality white, at $\mathrm{t}_{2} b$ with the quality light grey, at $\mathrm{t}_{3} c$ with the quality grey, at $\mathrm{t}_{4} d$ with the quality dark grey)

In this case the constants $a-d$ are to be taken as not being identical and as expressing the shifting sense of the identity of the property. Catherine's case will look slightly but importantly different:

(c') The cube is (at $\mathrm{t}_{1} a$ with the quality white, at $\mathrm{t}_{2} a$ with the quality light grey, at $\mathrm{t}_{3} a$ with the quality grey, at $\mathrm{t}_{4} a$ with the quality dark grey)

In this case, the constant $a$ is identical across the sequence and expresses what I have called the sense of identity of the property. That the sense of identity of the property remains constant across the entire sequence accounts for why Catherine perceives the property as constant even though her sense of the quality of the property varies across the sequence.

It is important to note that we need a sense of identity not only in order to explain cases where we continually experience some kind of perceptual explosion or illusion. It is also needed in order to account for cases such as (d), where the perceptual content presents us with an ever more determinate property across a perceptual sequence. In these cases the sense of quality is also changing.

Diana perceived a property as continuously more determinate. In her case, the part of the perceptual content presenting the colour of the ball would have the following structure:

(d') The ball is (at $\mathrm{t}_{1} a$ with the quality coloured, at $\mathrm{t}_{2} a$ with the quality dark, at $\mathrm{t}_{3} a$ with the quality blue, at $\mathrm{t}_{4} a$ with the quality navy blue) 
Once again, the sense of identity of the property explains how we can see the ball as having the same colour, even though the sense of the quality of the colour varies across the sequence.

The lesson from cases (c) and (d) is that one can be perceptually related to a property even though the perceptual content does not present the exact quality of the property. Catherine's sense of quality is not veridical. Diana is not until the end of the sequence presented with a lowest determinate of the property. Yet in both cases they are throughout their respective sequences perceptually related to the same property. So a correct presentation of the quality of the property is not necessary for being perceptually related to a property (cf Mulligan 1995, 216 for a similar conclusion).

In this section I have argued that the perceptual content presenting an object as having a certain property consists of one sense presenting the object, one sense presenting the identity of the property, and one sense presenting the quality of the property. The natural question now is what the sense of identity and the sense of quality of a property refer to. This is the topic of the next section.

\section{Perceiving Tropes}

Let me begin this section by discussing what the sense of quality might refer to. In one sense, this problem has a rather simple solution. If we see an object as spherical and white, there is one sense of quality that accounts for why we see the object as spherical and another that accounts for why we see the object as white. The sense of quality is in other words what accounts for the fact that we see objects as being in certain ways. So, when the sense of quality is veridical, the sense of quality refers to whatever it is that makes white objects white and spherical objects spherical.

But in another sense, the solution to this problem is quite difficult. For it is a highly intricate question what it is that makes white objects white and spherical objects spherical. We can restrict the range of answers by assuming that there are properties and that these exist in re, that is, that they exist in ordinary substances. At this point we have to ponder whether universals figure in the solution to our problem or not. First, it might be held that there are no universals. It is tropes that make white objects white. Resemblance among objects is explained by the fact that different tropes can belong to the same resemblance class. Thus, what makes it the case that we perceive two properties as similar would be the fact that we perceive different tropes as belonging to the same resemblance class. On such an account, the sense of identity of a property would presumably refer to a trope and the sense of quality to a resemblance class of some kind.

On an alternative approach, we might assume that it is universals that make white objects white and spherical objects spherical. On such an account, the sense of quality would refer to a universal. Thus, what makes it the case that we perceive two objects as resembling each other would be the fact that we perceive them as exemplifying the same universal.

In the present paper I shall for the sake of simplicity assume that the sense of quality refers to a universal. One reason for this is dialectical - if we assume that the sense of quality refers to a resemblance class of tropes, we would have to assume that perceptions refer to tropes. But one of the purposes of this paper is to argue that we can perceive tropes. So that would beg the question. Another reason for this assumption is that I believe it to be correct. I believe that there are both universals and tropes, and that we can see both universals and tropes.

Let us now consider what the sense of identity of a property might refer to. If there are universals, one might suppose that both the sense of quality and the sense of identity refer to universals. But the problem with such an account is that it cannot explain perceptual 
explosions. What characterises a property explosion is that the sense of quality is shifting over time, even though the sense of identity remains unchanging. But if the sense of quality and the sense of identity have the same reference, this would be problematic. For on such an account it would be hard to explain how the sense of quality might change but not the sense of identity.

But here it might perhaps be objected that the sense of identity does not refer to a determinate universal, but rather to a determinable universal. So, for example, whereas the sense of quality in a perceptual explosion first refers to cubicity and then to sphericity, the sense of identity would throughout the process refer to the determinable property being shaped.

Now, it might well be that we perceive determinables when we perceive determinates (Johansson 2000, 114ff.). But even if that is the case, the sense of identity cannot refer to determinables. In order to see this, let us once again return to the case of Brian. He is seeing the object change its colour. It goes from white to dark grey. But in this process the determinable colour will remain constant. He is seeing the object as coloured throughout the perceptual process. So the presentation of the determinable is not changing. But Brian is experiencing precisely a shifting sense of identity across this sequence. That is what distinguishes his case from that of Catherine's case. So the sense of identity cannot be identical to the content presenting him with a universal determinable. ${ }^{7}$

But perhaps it might be argued that the sense of identity does not refer to a property at all, but rather to the object exemplifying the property? If the sense of identity refers to the object exemplifying the property, we would indeed have a nice explanation of cases involving property-constancy. But unfortunately such an account would fail to explain cases involving property change. For when we perceive that an object is changing in some way, the sense of identity of the property is changing. The object itself is however perceived as persisting. It is the same object that is perceived as exemplifying different properties over time. So it cannot be the case that the sense of identity (which is changing) derives its identity from the presentation of the object. For the object exemplifying the property is perceived as identical over time.

If the analysis so far is correct, the sense of identity does not refer to a universal. Nor does it refer to any substance. Could the sense of identity refer to some other entity? I have a hard time seeing what that entity might be, and I think that we may safely conclude that the conclusion so far must be that the sense of identity refers to a non-universal aspect of the property itself.

But the only non-universal aspect of a property that there could possibly be is the particularity of a property. If you perceive two different balls as white, only to realise in a perceptual explosion that one of the balls was not white after all, but rather grey, the senses of identity of the colour-properties of the balls are not changing. But it is patently not the case that they refer to the same entity. The sense of identity referring to the colour of the grey ball is clearly different from the sense of identity referring to the colour of the white ball. But since the senses of identity have not changed throughout the perceptual process, they must have been different from the beginning - where both balls were perceived as white.

Consequently, it is the case that not even two objects which are perceived to exactly resemble each other or exemplify the same universal can be perceived to have identical properties.

But if this is the case, no two objects could ever be presented as having identical properties. The sense of identity of a property presented as exemplifying one object could never be identical to the sense of identity of a property presented as exemplifying another object.

\footnotetext{
${ }^{7}$ It is obviously possible to avoid this consequence by arguing that the sense of identity refers to a determinabletrope. But that would be tantamount to accept that we perceive properties as tropes, which is the main claim in this section.
} 
Properties are consequently presented as unrepeatable in the same way as the substances that are presented as exemplifying them. The sense of identity of a property refers to the particularity of a property. It refers to a trope.

\section{An Argument Against Property-Involving Accounts of Phenomenal Character}

If my arguments thus far are correct, they have important implications for the nature of the phenomenal character of our perceptions. More specifically, they indicate that perceptual experiences are not object-involving. Or, at the very least, they indicate that perceptual experiences are not constituted by the properties of the object perceived. The notion that the perceived object and its properties feature as constituents in perceptual experiences is a position that has been defended from two quite different angles in recent years. Thus, we find the position defended both by disjunctivists and by intentionalists subscribing to the notion that the phenomenal character of a perceptual experience is identical to the Russellian intentional content of the said experience.

The central tenet of disjunctivism is that veridical perceptual experiences are objectinvolving, in the sense that the objects perceived feature in perceptual experiences, whereas non-veridical perceptual experiences are experiences of a different nature. We thus find Brewer declaring that "perception is an openness to, or acquaintance with, mind-independent empirical things themselves, whose basic natures and perceptible qualities constitute what it is like to be presented with them in this way" (Brewer 2004, 69). John Campbell on the other hand claims that "the phenomenal character of your experience, as you look around the room, is constituted by the actual layout of the room itself: which particular objects are there, their intrinsic properties, such as colour and shape, and how they are arranged in relation to one another and to you" (Campbell 2002, 116). And the same idea can be found in the work of Michael Martin: "Some of the objects of perception - the concrete individuals, their properties, the events these partake in - are constituents of the experience" (Martin 2004, 39).

So what characterises veridical perceptual experiences on the disjunctivist account is that the objects themselves enter into the perceptual experience. The same claim is also present in many intentionalists who believe that the phenomenal character of a perceptual experience is identical to its Russellian content. Here is for example a representative passage from Michael Tye:

To see why, consider again what the thesis of transparency tells us. It tells us that in the case of perceptual experiences, the only qualities of which we are introspectively aware are qualities of external things if they are qualities of anything at all. But intuitively, we are aware of phenomenal character when we introspect. The conclusion to draw is that the phenomenal character of a perceptual experience consists in, and is no more than the complex of qualities the experience represents. Thus, the phenomenal character of the experience of red just is red. In being aware of red, I am aware of what it is like to experience red, since what it is like to experience red is simply red. (Tye 2009, 119)

So, on Tye's account, perceptions are transparent. We are not aware of anything but the intentional content of the experience. The intentional content however is constituted by the properties of the object of the perception. So the phenomenal character is constituted by the properties of the object of perception as well (cf. Dretske 1995, Tye 1995, Thau 2002).

It is important to note that on the Russellian conception, both veridical and non-veridical perceptions have Russellian content. Non-veridical perceptions are however not conceived as 
object-involving in the sense that they contain the purported (and non-existing) object of perception. They do however contain the properties the non-existing object is presented as having. Here is David Chalmers explicating this position (which he does not defend):

My visual experience when I look at a green ball has a certain object-involving content, but it seems that a phenomenally identical experience could lack that content, if I were looking at a different object, for example, or if I were hallucinating. (Some direct realists will deny this claim, but most contemporary representationalists accept it.) But in these cases, the propertyinvolving content of the original experience is still plausibly present: my visual experience still represents that there is a green object in front of me. (Chalmers 2004, 167)

So the Russellian intentionalist will claim that intentional content is even in non-veridical cases constituted by the properties the perception is about. This seems to differentiate the Russellian from the disjunctivist.

The disjunctivist and the Russellian offer a similar account of veridical perceptual experiences. If we perceive an entity and its properties, these properties feature as the constituents of the phenomenal character of the visual perception. On both accounts, veridical perceptions are property-involving in the sense that they are constituted by the properties of the object perceived.

In order to see what is wrong with such accounts we need to make the assumption that there are tropes. This is an assumption that the defender of property-involving content would better accept. For if my argument so far is correct, we can only perceive properties as tropes. So if perceptual content can present us with tropes, the defender of property-involving content would have to accept that there are tropes. Any veridical perceptual experience of a trope would on the property-involving theory of perception have the trope itself as a constituent.

Let us now proceed to consider whether perceptual experiences can be object-involving or property-involving in the sense that they have the tropes perceived as constituents. I shall argue that this is not the case. I have two arguments. First, property-involving accounts of phenomenal character cannot explain perceptual explosions. Secondly, they cannot explain cases of determinable-constancy.

Consider first of all the case of Catherine! She approaches a cube that she initially perceives as white. However, she experiences a perceptual explosion and starts perceiving the cube as grey. If my account is correct, the sense of identity of the property will remain invariant. But the sense of quality of the property will change.

Whereas one object can change with respect to which property it exemplifies, tropes themselves cannot change. A trope cannot first exemplify one universal and subsequently exemplify another universal. ${ }^{8}$ But clearly, perceptual explosions involve a change with respect to the property presented. In the case of Catherine, the trope is first presented as white, and subsequently as grey. But no trope could be first white and then grey. So, clearly, the trope itself is not a constituent of Catherine's perceptual experience. For Catherine's perceptual experience is changing with respect to colour, but the trope is not changing.

There are two possible ways to object to this argument. First of all, it might be argued that the trope is a constituent of the perceptual experience before and after the explosion. But this objection fails to explain the fact that the perception explodes. The sense of quality of the perception is changing in a perceptual explosion. But the perceived trope is not changing. So it is hard to see how the purported presence of the trope in the perceptual experience could explain the fact that the perception explodes.

\footnotetext{
${ }^{8}$ Tropes can however change the relations they bear to various entities. They can also change position in spacetime. But this obviously does not mean that they can exemplify different universals, merely that they can be the relata of different relations.
} 
A second objection is more promising. It might well be argued from a disjunctivist point of view that the perceptual explosion consists of one veridical experience and one non-veridical experience. So, the trope perceived is only present in the veridical experience, but not in the non-veridical experience.

Any such account would however fail to explain our original distinction between perceptions of change and perceptual explosions. For consider a case where someone, let us call him Colin, would erroneously perceive that an object changed from white to grey. In this case the object would be grey throughout the perceptual process, but Colin would perceive the object changing from white to grey. So, presumably, his perception is only property-involving after the perceptual presentation of change.

The problem is that if Catherine's perceptual experience before the explosion is not property-involving, there would be nothing on the property-involving account that distinguished her experience from the experience of Colin. Both initially perceive the object as white. When they do this, the experience is by assumption not property-involving. But it is property-involving when they perceive the object as grey. But then it is hard to see what the difference could be between the two cases.

The problem that perceptual explosions raises for the disjunctivist and the Russellian is that if the property is involved in the perception before and after the explosion, it becomes very hard to explain what it is that explodes. But if the property is only present in the perception after the explosion, it is hard to see how anything could explode. It will rather look like a normal perception of change. So, I conclude that Russellian and disjunctivist claims to the effect that perceptual experiences are property-involving cannot explain cases of perceptual explosions.

My second argument is that property-involving accounts cannot explain cases of determinable-constancy. Determinable constancy involves cases where the sense of identity is invariant, but where the sense of quality becomes more (or less) determinate. Thus, Diana goes from successively perceiving a ball as dark to navy blue. But she does not perceive the ball change with respect to colour.

Let us now make the assumption that Diana's perception is veridical throughout the perceptual process. It is clearly not the case that she is hallucinating or having an illusion. The ball is really navy blue. So, her successive perceptions of the ball as dark, blue and navy blue are all veridical.

It seems to me that there are two good reasons to believe that these cases show that perceptions are not property-involving. First of all, if Diana's perception of the ball as blue were veridical, the perceptual experience would not be constituted by the property navy blue, but rather by the property blue, where the latter has navy blue as one of its possible determinates. The determinate property navy blue would not be a constituent of the perceptual experience at that moment in time since the object is not perceived as navy blue.

So the property-involving account of phenomenal character would have to defend the notion that there are properties that are neither highest determinables nor lowest determinates.

Diana's ball would have an almost infinite amount of colour tropes, one making it navy blue, another making it blue, yet a further trope making it dark, and so on and so forth.

Now, there are some philosophers who defend the notion that there are properties of the highest determinable in addition to those of the lowest determinate (Johansson 2000). But the present claim would lead to a highly inflated ontology where there would be properties for every position in between the highest determinable and the lowest determinate. And whereas there are some philosophers (Wilson 2012, Matthen 2005, 101ff.) who seem to accept that there can be properties lying between the highest determinable and the lowest determinate, it is a very controversial position. And the present author, for one, has a very hard time seeing why we should accept such an ontological inflation. 
But even if we for some reason were to accept that there are properties which are neither lowest determinates nor highest determinables, there is a second problem with the propertyinvolving account of determinable-constancy. Even if Diana's ball had a blueness-trope, that would be a different trope than the navy-blue trope. So, in this case there would, after all, be successively different tropes involved in her perceptions. But then she would not, after all, perceive the same trope over time. The sense of identity of the property would therefore not be invariant.

\section{Phenomenal Tropes and the Perception of Properties}

I have argued that the phenomenal character of a visual experience is not property-involving. But there is nevertheless a sense in which the phenomenal character of a visual experience is constituted by tropes. If we assume that there are properties, it is reasonable to assume that phenomenal states have properties too. And if properties are tropes, then the phenomenal character of the perception will be constituted by tropes as well. These tropes are however not mind-independent - as the disjunctivist and the Russellian would claim. Following Kriegel (2004), we may call these tropes "phenomenal tropes".

If we assume that there are phenomenal tropes, we can easily explain the problematic cases of property-constancy. Senses of identity and senses of quality might presumably be identified with phenomenal tropes. Both make a contribution to the overall phenomenal character of the perceptual experience, and they are not properties of the object perceived. Presumably, they bear an intricate relationship to each other. I would suggest that senses of identity supervene on a successive series of senses of qualities.

Consider once again the case of Diana. It is true that the phenomenal character of her perceptual experience is changing. Consequently, a succession of different phenomenal tropes may constitute a succession of senses of qualities: one representing dark, one representing blue and one representing navy blue. A phenomenal trope constituting the sense of identity would then supervene on this sequence. Whereas some of these tropes may well fail to represent the lowest determinate of the property colour, the phenomenal tropes themselves may well be of the lowest determinate. Something similar would be true of propertyexplosions. Only in this case the phenomenal tropes involved would be different. However, a full defence and elaboration of these ideas falls beyond the scope of the present paper. ${ }^{9}$

\section{References}

Brewer, Bill 2004: "Realism and the Nature of Perceptual Experience". Philosophical Issues $14,61-77$.

Burge, Tyler 2010: Origins of Objectivity. Oxford: Clarendon Press.

Campbell, John 2002: Reference and Consciousness. Oxford: Clarendon Press.

\footnotetext{
${ }^{9}$ Thanks are due to Ingvar Johansson, David Woodruff Smith, Kristoffer Sundberg, Christer Svennerlind, the members of the Eidos Seminar in Geneva and an anonymous reviewer for many valuable comments on a previous version of this paper. The writing of this paper was funded by The Swedish Research Council (Research Grant 421-2011-1587).
} 
Campbell, Keith 1981: “The Metaphysic of Abstract Particulars”. Midwest Studies in Philosophy 6, 477-488.

Chalmers, David 2004: "The Representational Character of Experience”. In:Brian Leiter (ed.), The Future for Philosophy. Oxford: Clarendon Press, 153-181.

Chalmers, David. 2006: "Perception and the Fall from Eden". In: Tamar Szabó Gendler \& John Hawthorne (eds.), Perceptual Experience. Oxford: Clarendon Press, 49-125.

Dretske, Fred 1995: Naturalizing the Mind. Cambridge Mass.-London: The MIT Press.

Husserl, Edmund 1901 (1975/1984): Logische Untersuchungen. Zweiter Band. As reprinted in: Ursula Panzer (ed.), Husserliana XIX/1 and XIX/2. The Hague: Nijhoff.

Johansson, Ingvar 2000: “Determinables as Universals”. The Monist 83, 101-121.

Johnson, W. E. 1921: Logic Part I. Cambridge: Cambridge University Press.

Johnston, Mark 2004: "The Obscure Object of Hallucination". Philosophical Studies 120, 113-183.

Kitaoka, Akiyoshi 2006: “Anomalous Motion Illusion and Stereopsis". Journal of Three Dimensional Images 20, 9-14.

Kriegel, Uriah 2004: "Trope Theory and the Metaphysics of Experiences". American Philosophical Quarterly 40, 5-20.

Levinson, Jerrold 2006: "Why There Are No Tropes”. Philosophy 81, 563-579.

Lowe, E. J. 1998: The Possibility of Metaphysics. Substance, Identity and Time. Oxford: Clarendon Press.

Lowe, E. J. 2006: The Four-Category Ontology. A Metaphysical Foundation for Natural Science. Oxford: Clarendon Press.

Lowe, E. Jonathan 2008: “Tropes and Perception". In: Simone Gozzano \& Francesco Orilia (eds.), Tropes, Universals and the Philosophy of Mind. Essays at the Boundary of Ontology and Philosophical Psychology. Frankfurt: Ontos Verlag, 175-192.

Martin, Michael 2004: “The Limits of Self-Awareness”. Philosophical Studies 120,37-89.

Matthen, Mohan 2005: Seeing, Doing and Knowing. A Philosophical Theory of Sense Perception. Oxford: Clarendon Press.

Mertz, D. W. 1996: Moderate Realism and its Logic. New Haven: Yale University Press.

Mulligan, Kevin, Simons, Peter \& Smith, Barry 1984: “Truth-Makers”. Philosophy and Phenomenological Research 44, 287-321. 
Mulligan, Kevin 1995: "Perception”. In: Barry Smith \& David Woodruff Smith (eds.), The Cambridge Companion to Husserl. Cambridge: Cambridge University Press, 168-238.

Mulligan, Kevin 1999: "Perception, Particulars and Predicates". In: Denis Fisette (ed.), Consciousness and Intentionality: Models and Modalities of Attribution. Dordrecht: Kluwer Academic Publishers, 163-194.

Nanay, Bence 2012: "Perceiving Tropes”. Erkenntnis 77:1-14.

Searle, John 1983: Intentionality. An Essay in the Philosophy of Mind. Cambridge: Cambridge University Press.

Siegel, Susanna 2010: The Contents of Visual Experience. Oxford-New York: Oxford University Press.

Smith, David Woodruff 1979: "The Case of the Exploding Perception”. Synthese 41, 239269.

Smith, David Woodruff 1984: "Content and Context of Perception”. Synthese 61, 61-87.

Smith, David Woodruff 1986: "The Ins and Outs of Perception". Philosophical Studies 49, 187-211.

Smith, David Woodruff 1989: The Circle of Acquaintance. Perception, Consciousness, and Empathy. Dordrecht- Boston-London: Kluwer.

Svennerlind, Christer 2008: Moderate Nominalism and Moderate Realism. Göteborg: Acta Universitatis Gothoburgensis.

Thau, Michael 2002: Consciousness and Cognition. Oxford-New York: Oxford University Press.

Tye, Michael 1995: Ten Problems of Consciousness. Cambridge, Mass.-London, England: The MIT Press.

Tye, Michael 2009: Consciousness Revisited. Cambridge: MIT Press.

Wade, Nicholas .J. 1977: "Distortions and Disappearances of Geometrical Patterns". Perception 6, 407-433.

Williams, Donald C. 1953: “The Elements of Being: I-II”. Review of Metaphysics, 7: 3-18, 171-192.

Wilson, Jessica 2012: “Fundamental Determinables”. Philosophers' Imprint 12, 1-17. 